\title{
HUBUNGAN KUALITAS PELAYANAN TERHADAP KEPUASAAN PELANGGAN PADA KANTOR PERUSAHAAN DAERAH AIR MINUM DI KOTA SAMPIT KABUPATEN KOTAWARINGIN TIMUR
}

\section{Relationship of Service Quality to Customer Satisfaction in Regional Water Company Office in Sampit City, East Kotawaringin Regency}

\section{Indah Tri Handayani*}

Fitri Marlita

Universitas Muhammadiyah Palangkaraya, Palangka Raya, Central Kalimantan, Indonesia

email: indahtry.it@gmail.com

\section{Kata Kunci:}

Kualitas Pelayanan

Kepuasan Pelanggan

PDAM

\section{Keywords: \\ Service quality \\ Customer satisfaction \\ PDAM}

\section{Accepted}

August 2017

\section{Published}

October 2017

\begin{abstract}
Abstrak
Penelitian ini bertujuan untuk mengetahui dan menganalisa seberapa besar hubungan kualitas pelayanan jasa terhadap tingkat kepuasan yang dirasakan oleh pelanggan yang menggunakan jasa Perusahaan Daerah Air Minum (PDAM). Metode penelitian yang digunakan dalam penelitian ini adalah metode observasi, kuesioner dengan mengunakan skala likert dan metode penentuan sampel yang digunakan adalah taraf kesalahan 10\% sebanyak 162 sampel, tipe penelitian yang digunakan Kuantitatif Asosiatif yaitu untuk mencari hubungan kualitas pelayanan tehadap kepuasan pelanggan. Pengujian hipotesis yang digunakan adalah uji statistik dengan rumus "Product Moment Person". Terdapat hubungan yang sangat erat antara kualitas pelayanan terhadap kepuasan pelanggan, dari hasil perhitungan dengan menggunakan metode korelasi product moment person di dapat nilai rxy sebesar 0,996 menurut pedoman untuk memberikan interprestasi koefisiensi nilai tersebut berada antara 0,8-1000. Hal ini dapat dibuktikan bahwa semakin baik atau meningkatnya pelayanan yang di berikan oleh PDAM maka, semakin tinggi tingkat kepuasan pelanggan PDAM.
\end{abstract}

\section{PENDAHULUAN}

Pelayanan adalah kunci keberhasilan dalam berbagai usaha atau kegiatan yang bersifat jasa. Oleh karenanya, apakah pelayanan dalam bidang lain seperti pelayanan dalam pembayaran loket, pengaduan gangguan, pemasangan baru, kualitas air bersih atau pembacaan meteran yang dilakukan PDAM dapat terlaksana dengan baik. Walupun itu termasuk hal kecil, tetapi sangat berpengaruh bagi pihak yang bersangkutan untuk menentukan pelayanan yang akan diberikan dapat benar-benar memuaskan pelanggan atau tidak.

Oleh karena itu, PDAM Kota Sampit dituntut untuk dapat melakukan segala upaya perbaikan dan penyempurnaan dalam meningkatkan kualitas pelayanan air minum yang telah menjadi kebutuhan bagi masyarakat banyak, pada saat ini PDAM dinilai masih rendah dalam cakupan pelayanan ini disebabkan kualitas airnya kurang bersih yang ada dilapangan yang melayani penyambungan pelanggan 
serta mencatat meteran yang tidak sesuai dengan pemakaian PDAM oleh masyarakat. Untuk itu dilakukan upaya perbaikan dan penyempurnaan kualitas pelayanan air minum, ini diharapkan dapat tercapainya PDAM dengan kinerja organisasi yang efektif dan efisien. Menghadapi kondisi tersebut perlu dilakukan penilaian kualitas pelayanan, agar segala pengambilan keputusan dan penentuan kebijakan dapat ditelaah dan dievaluasi apakah sudah dilakukan secara tepat dan objektif.

Perusahaan Daerah Air minum Kota Sampit Kabupaten Kotawaringin Timur memiliki jumlah pelangan 112.890, yang mana tugas PDAM merupakan abdi masyrakat dalam memberikan pelayanan diharapkan mempunyai sikap mental, tekad dan semangat, ketaatan dan kedisiplinan untuk tugastugasnya yang sesuai dengan keahlianya masingmasing, sehingga dapat memenuhi kebutuhan masyarakat pengguna jasa dan diharapkan dapat memberikan pelayanan yang baik kepada pelanggan serta mendatangkan kepuasan kepada masyarakat.

Sampara (Hardiyansyah, 20II) mengemukakan bahwa kualitas pelayanan adalah pelayanan yang diberikan kepada pelanggan sesuai dengan standar pelayanan yang telah dibakukan sebagai pedoman dalam memberikan layanan. Standar pelayanan adalah ukuran yang telah ditentukan sebagai suatu pembakuan pelayanan yang baik. Kualitas pelayanan merupakan suatu kondisi dinamis yang berhubungan dengan produk, jasa, manusia, proses dan lingkungan dimana penilaian kualitasnya ditentukan pada saat terjadinya pemberian pelayanan publik tersebut

Dengan dilakukan penilaian kualitas pelayanan ini, maka segala pengambilan keputusan dapat ditelaah apakah sudah dilakukan secara tepat dan objektif. $\mathrm{Hal}$ ini, juga berguna untuk mengetahui dan mengevaluasi pelaksanaan kualitas pelayanan dan membandingkan dengan rencana kerja serta melakukan tindakan untuk memperbaiki kualitas
Pelayanan periode berikutnya. Sehingga dari adanya permasalahan di atas membuat peneliti ingin mengangkat judul Pengaruh Kualitas Pelayanan Terhadap Kepuasan Konsumen Dikantor PDAM di Kota Sampit Kabupaten Kotawaringin Timur.

\section{METODOLOGI}

Metode yang digunakan dalam melakukan penelitian ini yaitu menggunakan data kuantitatif. Penelitian asosiatif merupakan penelitian yang bertujuan untuk mengetahui hubungan antara dua variabel atau lebih. Jenis penelitian ini merupakan penelitian asosiatif kuantitatif yaitu penelitian yang berusaha mencari hubungan antara satu variabel dengan variabel lainnya. Penelitian ini mengukur tentang Hubungan Kualitas Pelayanan terhadap kepuasan pelanggan Dikantor PDAM Kota Sampit Kabupaten Kotawaringin Timur. Dalam pengumpulan datanya menggunakan angket, hasil data tersebut kemudian dinyatakan dalam bentuk angka (Kuantitatif).

\section{HASIL DAN PEMBAHASAN}

Kualitas pelayanan adalah terpenuhinya harapan pelanggan sesuai keinginan pelanggan. Untuk menunjang kepuasan pelanggan, maka salah satu upaya yang dilakukan oleh setiap perusahaan khususnya perusahaan yang bergerak dibidang jasa penyaluran air minum sangat perlu memberikan penerapan kualitas pelayanan, sebab dengan adanya peningkatan kualitas pelayanan, maka akan dapat mempengaruhi kepuasan pelanggan. Dalam meningkatkan kualitas pelayanan pelanggan pada PDAM Kota Sampit Kotawaringin Timur, maka perlu dilakukan pembahasan mengenai kualitas pelayanan. $\mathrm{Hal}$ ini bertujuan untuk dapat melihat sebagian besar pengaruh kualitas pelayanan yang diberikan oleh PDAM, adapun dimensi-dimensi kualitas pelayanan yang meliputi Tangible, Reliability, Responsivenss, Assurance, emphaty. 
Kepuasan berasal dari kata "puas" yakni pernyataan perasaan atas suatu hal, sedangkan kepuasan pelanggan adalah hasil dari persepsi pelanggan dari nilai yang diterima dalam transaksi atau hubungan dimana nilai sama dengan kualitas pelayanan yang dirasakan relatif terhadap harga dan biaya yang dikeluarkan pelanggan. Kepuasan adalah perasaan senang atau kecewa seseorang yang timbul karena membandingkan kinerja yang dipersepsikan produk (atau hasil) terhadap ekspetasi mereka. Tidak semua pelanggan memiliki nilai yang sama bagi perusahaan. Kepuasan konsumen dipengaruhi oleh keadilan yang dirasakan, harapan yang dibuat oleh konsumen dan perlaksanaan actual dari pelayanan.

Kepuasan dapat dipengaruhi oleh perbandingan konsumen atas kualitas pelayanan yang diberikan dengan yang diharapkan oleh para pelanggan. Beberapa pelanggan layak untuk untuk menerima perhatiaan dan pelayanan yang lebih dibandingkan dengan pelanggan lainya. Ada pelanggan yang tidak akan pernah memberikan umpan balik. Tidak peduli berapa banyak perhatian yang akan diberikan pihak PDAM yang akan diberikan kepadanya, dan tidak peduli seberapa puas mereka, dengan demikian antusiasme tentang kepuasan pelanggan harus dilakukan dengan analisis-analisis dari PDAM.

Berdasarkan hasil penelitian dan pembahasan yang telah dilakukan Pada penelitian mengenai Pengaruh Kualitas Pelayanan Terhadap Kepuasan Pelanggan dikantor PDAM maka dapat dikemukakan kesimpulan sebagai berikut Dari hasil perhitungan dengan menggunakan metode kolerasi product moment person didapat nilai rxy sebesar 0,996 menurut pedoman untuk memberikan interprestasi koefisiensi nilai tersebut berada antara 0,8-1000, dari analisis data dapat disimpulkan bahwa terdapat hubungan yang sangat kuat antara kualitas pelayanan terhadap kepuasan pelanggan PDAM. Hal ini dapat dibuktikan bahwa semakin baik atau meningkatnya pelayanan yang diberikan oleh PDAM maka semakin tinggi tingkat kepuasan pelanggan PDAM.

\section{KESIMPULAN}

Agar PDAM bisa lebih meningkatkan kepuasan pelanggan maka perlu melakukan beberapa perbaikan di fasilitas tempat kasir pembayaran dikarenakan masyarakat banyak mengantri lama saat melakukan pembayaran PDAM disebabkan loket pembayaran hanya ada satu jadi harus ada penambahan loketloket pembayaran dikantor PDAM. Perusahaan Daerah Air Minum diharapkan juga untuk meningkatkan keamanan dikarenakan berdasarkan hasil data yang diolah dari tanggapan responden. Keamanan di PDAM masih kurang sehingga perlu adanya penambahan security yang berjaga Ix24 jam.

\section{REFERENSI}

Achmadi, A. 2015. Kewajiban Pelayanan Publik Oleh Pemerintah Daerah di Era Otonomi. Anterior Jurnal. I4(2):22I-227.

Hardiyansyah, 20II. Kualitas Pelayanan Publik. Yogyakarta: Gaya Media.

Hutasoit, 20II. Pelayanan Publik. Jakarta: Magnascript Publishing.

Junaidi, J. 20I5. Kualitas Pelayanan Kenaikan Pangkat Pegawai Negeri Sipil Oleh Badan Kepegawaian Daerah Kabupaten Gunung Mas. Pencerah Publik. 2(I):49-55.

Lupiyoadi, Rambat dan Hamdani, A. 2006. Manajemen Penasaran Jasa. Jakarta: Salemba Empat,

Nurbudiyani, I. 2016. Pengaruh Kepuasan Kerja dan Lingkungan Kerja Terhadap Semangat Kerja Pegawai Universitas Muhammadiyah Palangkaraya. Anterior Jurnal. I6(1):7-13.

Nurhalina, N., Dadang, A., Gustinawati, R. 2017. Tingkat Kepuasan Konsumen Di Balai Laboratorium Kesehatan Provinsi Kalimantan Tengah Tahun 20I5. Jurnal Surya Medika (JSM). 3(I ):64-74.

Pasolong, Harbani. 2016. Teori Administrasi Publik. Bandung: Alfabeta. 
Sugiyono. 2007. Metode Penelitian Administrasi. Bandung: Alfabeta.

Syafrudin. 20II. Manajemen Mutu Pelayanan. Jakarta: Trans Info Media.

Tjiptono, Fandy. 2014. Pemasaran Jasa. Yogyakarta: Andi Offset. 